\title{
Correspondence
}

\section{Low-level laser therapy for migraine}

\author{
Marcio Rafael de Araujo Siega (iD Welber Sousa Oliveira \\ Modula Dor Clinic, Headache Outpatient Clinic, Brasília, Distrito Federal, Brazil
}

\section{$凶$}

marciosiega@gmail.com

Keywords:

Migraine Disorders

Low-Level Light Therapy Laser Therapy
Low-level laser therapy (LLLT) for the treatment of nociceptive, neuropathic, and musculoskeletal pain has been studied. To investigate its effectiveness in migraine, we used Medical Subject Headings terms in PubMed and found 5925 articles on LLLT since 1994. On using the term "pain," we found 490 articles since 2002. However, we only found one article using the terms "LTTT" and "migraine." We greatly appreciate the study by Loeb et al', which was conducted in Brazil. It compared treatment using botulinum toxin A with LLLT in patients with chronic migraine (CM) and demonstrated that both treatments are effective against $C M$. They followed the recommendations of the International Headache Society for research on CM and compared LTTT to an approved migraine treatment. ${ }^{2}$

Unlike other treatments and drugs proven to be effective against migraine, LTTT is non-invasive, safe, and inexpensive. Additionally, it can be a component of the interdisciplinary treatment of CM. Allodynia is very common in patients with $C M$ and can be a therapeutic target. ${ }^{3}$ This is because similar to botulinum toxin, it reduces central sensitization by modulating nociceptive transmission. ${ }^{4}$

We would like to highlight this article and draw attention to the lack of studies on the use of LLLT in patients with migraine. While the evidence of its benefit in acute and chronic neck pain exists ${ }^{5,6}$, future studies should assess its effectiveness in the prevention and treatment of migraine.

Author Contributions: MRAS - Preparation, writing, editing and supervision of the original, WSO Writing, editing and supervision of the original

Conflict of interest: None

Funding: No

Marcio Rafael de Araujo Siega

https://orcid.org/0000-0001-5006-1643

\section{References}

1. Loeb LM, Amorim RP, Mazzacoratti MD, Scorza FA, Peres MF. Botulinum toxin A (BT-A) versus low-level laser therapy (LLLT) in chronic migraine treatment: a comparison. Arq Neuropsiquiatr 2018;76(10):663-667 Doi: 10.1590/0004-282x20180109

2. Silberstein S, Tfelt-Hansen P, Dodick DW, Limmroth V, Lipton RB, Pascual J, Wang SJ. Guidelines for controlled trials of prophylactic treatment of chronic migraine in adults. Cephalalgia 2008;28(5):484-495 Doi: 10.1111/j.1468-2982.2008.01555.x

3. Dodick DW, Reed ML, Fanning KM, Munjal S, Alam A, Buse DC et al. Predictors of allodynia in persons with migraine: results from the migraine in America symptoms and treatment (MAST) study. Cephalalgia 2019;39(7):873-882 Doi: 10.1177/0333102418825346

4. de Tommaso M, Brighina F, Delussi M. Effects of botulinum toxin A on allodynia in chronic migraine: An observational open-label two-year study. Eur Neurol 2019;81(1-2):37-46 Doi: 10.1159/000499764

5. Chow RT, Johnson MI, Lopes Martins RA, Bjordal JM. Efficacy of lowlevel laser therapy in the management of neck pain: a systematic review and meta-analysis of randomized placebo or activetreatment controlled trials. Lancet 2009;374(9705):1897-1908 Doi: 10.1016/s0140-6736(09)61522-1

6. Pedro M, López-Pintor RM, Hoz-Aizpurua JL, Casañas E, Hernández DG. Efficacy of Low-Level Laser Therapy for the Therapeutic Management of Neuropathic Orofacial Pain: A Systematic Review. J Oral Facial Pain Headache 2020;34(1):13-30 Doi: 10.11607/ofph.2310 